Mag. Daniela

Brečko,

GV Izobraže-

vanje, d.o.o.

\title{
KARIERNI VZORCI V GLOBALNI DRUŽBI
}

\section{Od kariernih kompetenc do akumulacije kariernega kapitala}

\section{POVZETEK}

Avtorica v prispevku opisuje nove karierne vzorce oziroma nove načine načrtovanja kariere v globalnem okolju poslovanja. Navaja nekaj primerov kariernih poti, primerjalnih podatkov o povprečnem stevilu let, ki jih posameznik preživi v eni organizaciji, in najpogostejše razloge za karierne premike. Iz konkretnih opisanih primerov sklepa, da tradicionalne teorije kariernega razvoja ne morejo več odgovoriti na vprašanje, kako načrtovati kariero, temveč je tréba odgovore iskati v poglobljenem razmisleku o subjektivnih vzrokih in gonilih za karierne odločitve posameznika. Karierni razvoj namreč ni več predvidljiv, vertikalen, ampak prej spiralen. Avtorica ugotavlja, da je eno izmed pomembnih gonil kariernega razvoja želja po odkrivanju neznanega oziroma motivacija in želja po novem znanju. Posameznik oblikuje svoje delovno mesto v skladu s tem, kar zna in kaj se še želi naučiti. Ugotavlja, da niso le organizacije tiste, ki oblikujejo načine in oblike kariernega razvoja, temveč je vpliv vse pogosteje obraten posamezniks svojo karierno odločitvijo pomembno vpliva in oblikuje ekonomski in gospodarski razvoj družbe. V prispevku so predstavljene tudi kompetence za razvoj kariere ter pomen akumulacije kariernega kapitala za razvoj in rast posameznika.

Ključne besede: kariera, razvoj, izobraževanje, karierne kompetence, karierni kapital

\section{ZGODBA O KARIERI, KI JIH PIŠE ŽIVLJENJE ...}

"Matej je končal šolo pri sedemnajstih, pravzaprav jo je obesil na klin. Virtualni izzivi računalnikov so ga premamili in ni mu bilo več mar za šolo. Najbrž je bil za to nekoliko kriv tudi njegov oče, ki je vodil računalniško podjetje in ga spodbujal $k$ delu $z$ računalnikom. Matej se je zaposlil pri njem in njegovo učenje je bilo povezano z delom. Le dobri dve leti zatem je dobil mesto sistemskega inženirja pri potovalni agenciji, kjer je zamenjal kompleten računalniški sistem. Ob tem je navezal dobre stike z glavnim dobaviteljem računalniške opreme potovalne agencije, multinacionalnim podjetjem, zaprosil za službo pri njih in jo tudi dobil. Povzpel se je na mesto namestnika direktorja, kjer je bil prvič v karieri pred izzivom, da nadzoruje ljudi. Izziv je presegel njegovo trenutno znanje, ki je bilo vse doslej osredotočeno predvsem na stroko. Zato se je odločil pridobiti znanja s področja vodenja. Čez leto dni je zhova zaprosil za premestitev, tokrat $v$ prodajni oddelek. Tam se je naučil prodajati 
in spoznal ves prodajni proces, Le nekaj mesecev kasneje je dobil ponudbo za projektnega menedžerja na sedežu multinacionalke. Toda na obzorju so se že zbirali črni oblaki. Recesija je podjetje potisnila v fünančno krizo in rečeno mu je bilo, da v roku šstih mesecev ne bo imel več službe. Matej je do takrat nabral že veliko interdiciplinarnih znanj in predlagal vodstvu, da bi ustanovil svoje podjetje in s seboj vzel nekaj ljudi. Matejevo podjetje sedaj uspešno posluje že nekaj let in Matej je pri 38-ih letih starosti uspešen podjetnik."

\section{RAZVOJ KARIERE ALI RAZVOJ IZOBRAŽEVALNE POTI}

Pričujoča karierna zgodba mojega znanca me je navedla $\mathrm{k}$ razmišljanju, da je tradicionalni koncept kariere preživet in se umika novemu konceptu, to je vseživljenjskemu načrtovanju izobraževalne poti. Če Matej ne bi bil soočen $s$ toliko izzivi in učnimi priložnosti, ne bi nikoli mogel razviti interdisciplinarnosti, $\mathrm{ki}$ mu je na koncu omogočila ustanovitev in razvoj svojega podjetja.

Kar me prepričuje o nevzdržnosti klasiěnih teorij kariernega razvoja, ki bolj ali manj zatrjujejo, da je kariera niz delovnih vlog, ki posamezniku omogočajo plezanje po hierarhični strukturi, je predvsem porast "Matejevih zgodb", ki jih slišim skoraj vsak dan. Niso redki primeri, ko organizacije ponudijo posameznikom s posebnimi sposobnostmi velike materialne koristi - od zavidljive plače do prestižnih bonitet - $v$ zameno za to, da se redno zaposli pri njih. Posameznik pa bogato ponudbo zavrne s pojasnilom, da ne ve, kaj ga bo veselilo početi "jutri", in zato ne želi sklepati rednega delovnega razmerja. V ozadju te zgodbe se skriva želja po razširitvi učnega okolja.

Če se vrnemo na Matejevo karierno zgodbo, opazimo, da je njegova karierna pot prej po- dobna nepredvidljivi in spiralni poti kot pa napredovanju po točno določenih stopnjah.

$\check{\mathrm{Ce}}$ se ponovno vrnemo $\mathrm{k}$ Matejevemu primeru, opazimo, da je razvil pravzaprav vse tri tipe karier. Najprej profesionalno, pri čemer je razvijal računalniške spretno-

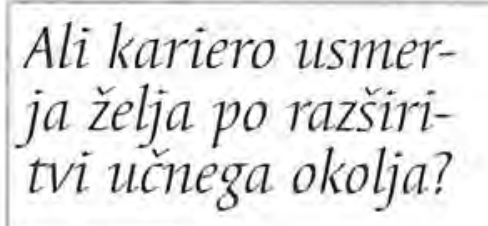
sti, potem se je povzpel kot menedžer in dosegel ugled znotraj organizacije, na koncu pa se je preizkusil kot podjetnik. Natančnejši pogled $v$ dinamiko njegove karierne poti nam daje vtis, da je Matej "v srcu" vselej bil podjetnik. Vselej je svoji osebnosti dodajal nove razsežnosti znanja in tako akumuliral karierni kapital. Matejeva zgodba nam lahko pomaga razumeti koncept "podjetniškega samorazvoja", ki nam odstira novo poglavje $v$ razvoju kariere tako posameznika kot tudi organizacij.

Več kot na dlani je, da teorija kariernega razvoja "Trait and Factor" in tudi vse druge statične teorije ne zmorejo več ponuditi zadovoljive analize novih kariernih vzorcev obnašanja. Ne zmorejo odgovoriti ne posamezniku, še manj pa organizacijam, kjer se delo vsak dan spreminja in so torej opisi del in nalog ter zahteve za opravljanje določenéga dela preteklost.

Iz Matejeve zgodbe izhaja dejstvo, da je karierni razvoj nepredvidljiv, predvidljivo pa

R. Kanter (2002) pravi, da je bolje kot o kariernem razvoju govoriti o karierni "Iogistiki", kjer razlikuje:

- profesionalno kariero, ki temelji na razvoju posebnih spretnosti in sposobnosti,

- menedžersko-birokratsko kariero, ki temelji na napredovanju po hierarhičnih stopnjah znotraj organizacije,

- podjetniško kariero, ki temelji na dodani vrednosti. 
je nenehno izobraževanje in učenje, s pomočjo katerega oblikujemo svoje delovno mesto in nenehno oblikujemo ter preoblikujemo delovno identiteto, Matej je kot kompulzivni Karierni vzorci $v$ globalni družbi postajajo nepredvidljivi. učenec oblikoval svoj karierni vzorec sam. V vsaki organizacijski/delovni vlogi, $\mathrm{ki}$ so se med seboj zelo razlikovale, je razvil nove kompetence, torej nova znanja, veščine hotenja in vrednote.

Pri načrtovanju kariere ga niso "vlekle" njegove sposobnosti, temveč prej vedoželjnost oziroma tisto, česar še ni znal. Star pregovor pravi, da partnerja ostaneta skupaj tako dolgo, dokler sta drug drugemu učitelja. Isto analogijo lahko opazujemo pri kariernem razvoju. Delavec tako dolgo ostane na enem delovnem mestu, dokler se lahko še kaj nauči in osebnostno razvija. Še včeraj bogokletna in utopična misel, da mora biti delovno okolje učilnica za vsakogar, se potrjuje skozi opazovanje novih kariernih vzorcev vedenja.

\section{Novi karierni \\ vzorci oblikujejo novo ekonomijo.}

Iz zgoraj opisanega primera namreč ne moremo več sklepati, da je razvoj kariere predvidljiv in načrtovan proces napredovanja od manj zahtevnih $\mathrm{k}$ bolj zahtevnim in uglednim ter bolje plačanim organizacijskim vlogam. Ljudje se odločajo za karierne premike, ki na prvi pogled nimajo "objektivnega vzroka". Ne napredujejo na višjo hierarhično raven ali pa se odločajo za karierne premike, kjer zaslužijo manj, kot so prej. Iz opisanega vzorca kariernega vedenja lahkó prej sklepamo, da gre za premike, katerih

razlog gre iskati v notranjih, subjektivnih, če želite, čustvenih vzgibih. Kot sem že predhodno omenila, opisana zgodba ni osamljen primer. Vse več ljudi načrtuje svojo kariero po nekih notranjih vzgibih.

\section{FOKUS KARIERE SE SPREMINJA}

Konvencionalno razmišljanje je, da organizacije in ekonomski model razvoja $\vee$ posameznih deželah oblikujejo karierne vzorce družbe in posameznikov, so torej okvir za načrtovanje kariere, povratni vpliv pa ni mogoč. Toda novi karierni vzorci še kako močno oblikujejo novo ekonomijo. Več kot očitno je, da je Matej sooblikoval ekonomijo z ustanovitvijo svojega podjetja.

Da se fokus kariere spreminja, je zaznati tudi iz svežih pristopov $\mathrm{k}$ oblikovanju delovnih mest. Sistematizacije del in nalog postajajo v hitro spreminjajoči se družbi prej ovira kot učinkovit kadrovski model, saj se zahteve in vsebina dela lahko čez noč spremenijo.

Nova ekonomija daje novincem boljša izhodišča, saj jih ne "oropa" za bonitete in privilegije starejših, status in rang se podrejata sposobnostim, učenje postaja centralna dejavnost vsakega posameznika in organizacije, pogostejše menjavanje delovnih mest pa prej prednost kot pa nelojalnost, saj to tudi pomeni, da se posameznik hitreje uči in da je akumuliral več znanja.

Vse to zahteva ponovni razmislek o kariernem razvoju ter globlji pogled $v$ subjektivne elemente kariernega razvoja in $\mathrm{v}$ sposobnost nenehnega učenja, kajti več kot očitno je, da je prav učenje in znanje glavni agregat kari-

Tradicionalno razmišljanje o karieri kot o nizu zaporednih korakov od spodaj proti vrhu preveva tudi ves pravni sistem, ki se ukvarja z delovno zakonodajo. Sistem je doživel napad s pojavom nove ekonomije, ki zahteva popolnoma novo zaposlitveno politiko. Tipičen primer zastarelega pravnega reda je minulo delo. Novi karierni vzorci namreč zahtevajo nove rešitve, ki morajo vključevati novo realnost: posameznik ne ostaja v organizaciji zaradi dolžine delovne dobe, temveč zaradi tržne vrednosti svojih sposobnosti in znanj. 
Stare teorije kariernega razvoja so bile razvite $v$ svetu in za svet, ki ga ni več, oziroma ga je vsak dan manj; to je bil svet stabilnih poklicnih kategorij, jasnih opisov del in nalog, $\mathrm{z}$ jasno in nedvoumno shemo napredovanja znotraj organizacije ... Namesto tega smo dobili organizacije, prepredene $\mathrm{z}$ informacijsko tehnologijo, globalizacijo poslovanja, neznosne pritiske konkurence, ki vznika za vsakim vogalom, razvoj sploščenih in bolj fleksibilnih organizacijskih oblik.

ernega razvoja. To je več kot razvidno tudi iz opisanega primera, pa ne le tega. Vsi zaposleni na svōj način generirajo svoje izkušnje, svoje znanje in gradijo svojo lastno socialno mrežo, kar vse skupaj tvori njihov karierni potencial.

$\mathrm{Ni}$ se spremenilo le delovno okolje, tudi ljudje, ki tvorijo delovno silo, so se spremenili. Karierna pričakovanja so postala zelo fleksibilna in predvsem zelo drugačna. Kakšne oblike kariernega vedenja bo razvila nova ekonomija, in obratno, kakšna ekonomija bo razvila nove karierne vzorce, sta vprašanji, ki presegata opus klasičnih teorij kariernega razvoja in postavljata $\mathrm{v}$ ospredje posameznika in njegovo pripravljenost na vseživljenjsko učenje in motiviranost za "izlete v neznano".

\section{IGRATI IGRO KARIERE V GLOBALNO-EKONOMSKEM TEATRU}

Ekonomski teater - oder, kjer vsi igramo vlogo delovnega življenja, se je torej korenito spremenil. V industrijski dobi je bilo to centralizirano gledališče, kjer je producent razpolagal $z$ velikim fondom denarja, kjer so pisatelji pisali elegantne scenarije in kjer je direktor izpilil predstavo do odličnosti po točno določenem načrtu. Izbira igralcev je bila sicer omejena, toda določena vnaprej. Za izbor je bilo treba pokazati nekaj malega sposobnosti, sicer pa je bilo vse skupaj odvisno od preprostega učenja vloge in sledenja direktorjevim navodilom in inštrukcijam. Ko smo zgradili svojo kariero v gledališču industrijske dobe, smo igralci začeli živeti varno življenje. Varnost je res bila, toda Drzniti si izlet $v$ neznano pomeni graditi kariero.

"brezbarvni" scenariji niso mogli privabiti na plan vsega potenciala igralcev. Bolj ko je bila produkcija dobra, manj je bilo možnosti razvoja, kajti ničesar novega se ni bilo moč naučiti. Enake vloge smo lahko igrali leta in leta, ne da bi nam bilo za to potrebno pridobivati nova znanja. Če se je pojavila nova vloga, jo je prevzel nekdo drug, ki jo je znova igral vrsto let ...

"Gledalisce indu-
strijske dobe" je
ponujalo varnost,
ne pa tudi razvoja.

Nova ekonomija pa je gledališče improvizacij, zlahka bi jo lahko primerjali s pouličnim gledališčem, Ideje so razpršene in prihajajo od vsepovsod, celo od obiskovalcev, meje med različnimi vlogami $v$ gledališču igralcev, producentov, piscev, direktorjev, "lučkarjev" - so izginile. Vsakdo lahko uporabi svojo iniciativnost in prevzame vodenje. Vloge se med seboj tudi mešajo; producenti in pisci so hkrati tudi igralci, scenariji so rezultat timskega dela in se od predstave do predstave spreminjajo, najustvarjalnejši del igre je improvizacija ...

Ko izgrajujemo kariero, smo pravzaprav vsi v vlogi igralcev. Kot taki iščemo organizacije in podjetja, ki "pišejo scenarije nam na kožo". Zdi se, da več kot scenariji dopuščajo improvizacije, zanimivejši so. Scenariji monotonega dela, jasni opisi del in nalog ter predvidljivo napredovanje postajajo stvar zgodovine. Na eni strani zagotovo zaradi tega, ker je informacijska revolucija sprožila plaz nenehnih sprememb, po drugi strani pa tudi "igralci" ne maramo več takšnih vlog. 


\section{TEATER NOVE EKONOMIJE}

Kaj se je torej spremenilo " $v$ teatru" nove ekonomije? Zagotovo se je povsem porušilo razmerje med mobilnostjo oz. stabilnostjo delovnih karier, Raziskava britanskega inštituta za delo je pokazala, da je leta 1993 že kar 61 odstotkov menedžerjev delalo za tri ali več

\section{"Teater nove ekonomije" ljubi improvizacije.} delodajalcev, v primerjavi z letom 1958, ko je tri ali več delodajalcev zamenjalo le 24 odstotkov menedžerjev. Zaposleni $\vee$ ZDA ostanejo povprečno $v$ eni službi štiri leta in pol, menedžerji pa v povprečju delajo le še šest let za istega delodajalca. Povprečna doba zaposlitve pri enem delodajalcu je na Japonskem 11 let, ne glede na to, da japonski sistem zaposlovanja pravzaprav nudi doživljenjsko zaposlitev. (Magiure, 1993) Vsi ti podatki dokazujejo, da karierni premiki niso zgolj posledica negotovih tržnih razmer, temveč prej odraz želje in motivov posameznika, da $v$

Le desetina zaposlenih ostaja $\mathrm{v}$ istem podjetju 20 let. novih organizacijskih vlogah obogati svojo osebnost in zadovolji željo po osebni rasti. Navedimo še nekaj predvidevanj, ki temeljijo na zbranih podatkih iz različnih raziskav. Sklepamo lahko, da bo le še 10 odstotkov zaposlenih ostalo $v$ podjetju še naslednjih 20 let. Preostalih 90 jih bo odšlo drugam.

Če smo se včasih spraševali, kaj izgublja posameznik, ki je zamenjal službo, si moramo danes postaviti prej obratno vprašanje, kaj izgublja posameznik, če predolgo časa vztraja v isti situaciji. Ali izgublja fleksibilnost in drugačnost? Kako lahko mobilnost doprinese $\mathrm{k}$ posameznikovemu učenju in, nenazadnje, kako lahko znanje posameznika, ki je prešel v novo organizacijo, to obogati in spremeni?
Menjava poklicev: Ne zastareva le tehnologija, ampak tudi poklici, katerih vsebina se korenito spreminja, nekateri pa celo izginjajo. Raziskava "The New Careers" (Arthur, 1994) je že pred skotajda desetimi leti pokazala, da le 61 odstotkov Britancev ostaja $v$ istem poklicu deset let, drugi ga v tem obdobju zamenjajo. Med omenjenimi 41 odstotki pa so pretežno starejši delavci in ženske.

Horizontalne in vertikalne kariere: Organizacije postajajo vse bolj sploščene in med generacijo $X$ je vse več tistih, ki jim laskava ponudba mesta menedžerja ne pride do živega. Napredovati vertikalno ali horizontalno $v$ sploščenih organizacijah izgublja pomen. Ljudje menjujemo ne le delodajalca, tudi poklic, panogo, lokacijo ... Vse več je tistih, ki gradijo ciklično kariero, torej izbirajo tiste aktivnosti, ki jim zagotavljajo profesionalni razvoj. Prav tako je vse več tistih, ki gradijo spiralno kariero, vpleteni so $\mathrm{v}$ različne aktivnosti, kar jih osebno izpopolnjuje in daje občutek rasti. Vsi ti pojavi me navajajo $\mathrm{k}$ trdnemu sklepu, da ljudje danes iščemo predvsem spodbudno učno okolje, ki nam bo zagotavljajo rast in razvoj. Delovne organizacije niso več bolj ali manj urejena delovišča, temveč bolj ali manj spodbudno in vznemirljivo učno okolje.

\section{RAZVOJ KARIERNIH KOMPETENC}

Marjeta si je izbrala poklic tajnice. Po raziskavah kariernih sider v Sloveniji (Brečko, 2001) sodi kar 95 odstotkov tajnic v karierno sidro predanosti. Za posameznike, zasidrane v sidru predanosti, je značilno, da želijo "služiti", biti predani eni stvari ali človeku. Vesna je bila tudi priznani fotomodel in manekenka, ki so ji pri 18 letih ponudili mikavno službo v sosednji Italiji. Toda službo je zavrnila in se raje zaposlila kot tajnica. Kmalu zatem se je poročila in postala mati dveh otrok. V 20 letih je menjala še nekaj služb, vedno pa se je znašla v vlogi nekoga, ki 
pomaga drugim. Tako je bila zaposlena kot negovalka v bolnišnici in nekaj časa kot negovalka v donu za ostarele, celo mesto receptorja je zasedala poldrugo leto dni. Danes je zopet tajnica in aktivno sodeluje $v$ Zvezi klubov tajnic Slovenije.

Če opazujemo Marjetino kariero, zlahka opazimo, da jo je pri vseh kariernih odločitvah vodila želja po predanosti, ki je bila tudi zares njeno karierno sidro. To sidro jo je vodilo in ni se mu odpovedala tudi $v$ najtežjih trenutkih ... Da bi ga izpolnjevala, se je odločala tudi za manj privlačne službe, za katere je bila celo preveč izobražena. Marjetin primer lepo ponazarja koncept kariernih kompetenc.

Ko je Marjeta "igrala" svojo kariero, se je ves čas učila. Njeno učenje je često spreminjalo smer. Njene temeljne kompetence so se razvijale skozi domačo vzgojo, šolske izkušnje in prvo delovno socializacijo. Na svoji karierni poti se je spoznala z različnimi "strankami" in se od njih marsikaj naučila. Ko je službovala kot negovalka, je naredila še tečaj za negovalko in tečaj prve pomoči ...

Da bi bolje razumeli Marjetine karierne kompetence, jih bom skušala primerjati z bolj poznanimi organizacijskimi "ključnimi kompetencami" (core competencies). Ključne kompetence vsake organizacije so osredotočene na tri temeljna področja:

- organizacijska kultura,

- ključna znanja "know-how" in

- socialni kapital oz. mreženje znotraj organizacije.

Karierne kompetence so na nek način komplementarne ključnim kompetencam organizacije in bi jih lahko definirali kot:

- vedeti zakaj (knowing-why),

- vedeti kako (knowing-how),

- vedeti kje ali od koga pridobiti pomoč (knowing-whom).
Če se povrnemo $k$ Marjetinem primeru, ga lahko ilustriramo s kariernimi kompetencami. Njene karierne kompetence na področju vedeti zakaj lahko najdemo $\mathrm{v}$ njenem trdnem kariernem sidru
Delovne organizacije postajajo ucilnice za vsakogar. pripadnosti in "služenja" stvarem oz. ljudem. Delo, pri katerem lahko pomaga drugim, jo osrečuje in daje smisel njenemu življenju in delu.

Vedeti kako: Karierne kompetence s tega področja so izkazane $v$ njenih bogatih delovnih izkušnjah, temeljnem izobraževanju in dodatnem usposabljanju. Osnovna znanja za opravljanje poklica tajnica si je pridobila $\mathrm{v}$ šoli, dodatna usposabljanja so nadgradila njene veščine, kako pomagati drugim, in hkrati razvile občutek za delo z ljudmi. Bogate delovne izkušnje pa so ji omogočile, da danes povsem samostojno vodi pisarno in nadomešča direktorja v njegovi odsotnosti.

Kompetence s področja vedeti kje se odražajo $\mathrm{v}$ njenih bogatih socialnih stikih s kolegi in kolegicami iz prejšnjih služb, v delu v Združenju klubov tajnic Slovenije in nenazadnje v prijaznih stikih $\mathrm{z}$ vsemi sodelavci $\mathrm{v}$ podjetju.

Karierne kompetence so pravzaprav osebne kompetence, ki imajo potencial, da postanejo

Kompetence na prvem področju vedeti zakaj se dotikajo osebnih vrednot, osebne identitete in iskanja globjega smisla $v$ delu ter so komplementarne $\mathrm{z}$ vizijo in poslanstvom organizacije. Prav tako kot mora organizacija vedeti, zakaj obstaja, mora posameznik vedeti, kaj je smisel njegovega dela. Karierne kompetence vedeti zakaj so glavni vir motivacije.

Kompetence vedeti kako obsegajo veščine, spretnosti in znanja, ki jih je posameznik pridobil skozi izobraževanje, usposabljanje in delo. Te kompetence se ves čas razvijajo in se odražajo $v$ tehniénih oz. menedžerskih znanjih in spretnostih.

Kompetence vedeti kje ali od koga pridobiti pomoč pa so sposobnost navezovanja in vzdrževanja učinkovitih odnosov in gradnja socialnih omrežij znotraj in zunaj organizacije. 
organizacijske kompetence oz. kljuěne kompetence posamezne organizacije ali podjetja.

Priložnost organizacij se skriva $v$ sposobnosti pretvoriti karierne kompetence $v$ organizacijske.
O kariernih kompetencah je bilo doslej zelo malo govora, veliko bolj pa so poznane tako imenovane vodstvene ali menedžerske kompetence. Zanimivo pri tem je, da se $\mathrm{v}$ zvezi $\mathrm{z}$ vodstvenimi kompetencami najpogosteje govori o tehničnih kompetencah, medosebnih kompetencah, strateških kompetencah ... Podjetja pogosto definirajo kompetence kot zahtevane spretnosti in znanja. Na eni strani se vprašajo, kakšne kompetence bi potrebovali za to, da bi dosegli strateške cilje, in na drugi strani, kakšne so obstoječe kompetence v podjetju. Razkorak

\section{Razvoj kariernega kapitala je osebna investicija $v$ pri- hodnost.}

so manjkajoče kompetence, ki jih je potrebno razviti ... Seveda, je zelo spodbudno, da organizacije veliko vlagajo $v$ zmanjševanje tega razkoraka in $\mathrm{v}$ razvoj kompetenc vedeti kaj. Velika škoda pa je, da sočasne pozornosti ne namenjajo tudi razvoju kompetenc vedeti zakaj in vedeti kje.

Če bi več pozornosti namenili tudi tema dvema vrstama kompetenc, bi izrazito povečali možnost za izmenjavo izkušenj in transfer znanja med organizacijo in zaposle-

Po scenariju, ki ga piše realnost globalne konkurence in učeče se družbe, načrtovanje kariere ni v raziskovanju, kako lahko posameznikovo kariero povežemo s cilji organizacije, temveč mora biti pot obratna. Pri načrtovanju kariere $\mathrm{v}$ globalnem okolju poslovanja gre prej za to, da pridobimo vpogled $v$ posameznikove karierne kompetence in presodimo, kako jih lahko vgradimo $\mathrm{v}$ organizacijsko učenje in kako lahko vodijo do novih poslovnih priložnosti. nimi. Zaposleni bi lahko gradili svojo identiteto $\mathrm{v}$ delovnem okolju, kjer bi imeli izjemno spodbudno okolje za samoučenje. Organizacije pa bi lahko na ta način pridobile veliko novega znanja, novih idej, novih poslovnih izzivov ...

\section{AKUMULACIJA KARIERNEGA KAPITALA}

Karierne kompetence, ki jih pridobimo $\mathrm{v}$ šoli, $v$ delovnem okolju in s pomočjo vseh drugih življenjskih izkušenj, se akumulirajo v tako imenovan karierni kapital. Karierni kapital lahko razvijamo, prav tako pa lahko skozi čas izgubi svojo vrednost. Razvijamo ga lahko z dodatnim izobraževanjem, usposabljanjem, prav tako pa skozi različnost življenjskih in delovnih izkušenj. Pri tem gre opozoriti, da določeni elementni kariernega kapitala niso priznani pri yseh delodajalcih. Izkušnja materinstva je najpogostejši element kariernega kapitala, ki ga delodajalci ne prepoznajo, kaj šele priznavajo. Pa vendarle matere menedžerke poročajo, da je transfer izkušenj materinstva povsem prenosljiv na področje vodenja. Verjetno bi lahko našli še kopico podobnih primerov.

Karierni kapital se zelo obogati $\mathrm{z}$ novimi delovnimi izkušnjami, zato imajo posamezniki, ki so večkrat menjali delovno okolje ali celo poklic, praviloma bogatejši karierni kapital. Veliko je takšnih, ki si ne upajo tvegati naložbe $v$ karierni kapital in prisegajo na varnost zaposlitve. Prav tako bi bile iz tega zornega kota tvegane investicije $\mathrm{v}$ zelo specifične sposobnosti oz. sposobnosti, ki niso prenosljive $\mathrm{v}$ druga delovna okolja oz. organizacijske vloge.

Vselej, ko se naučimo kaj novega, ko poglobimo smisel dela in obogatimo svojo socialno mrežo, vlagamo v karierni kapital. Povsem lahko bi naredili primerjavo med kariernim in finančnim kapitalom, med 


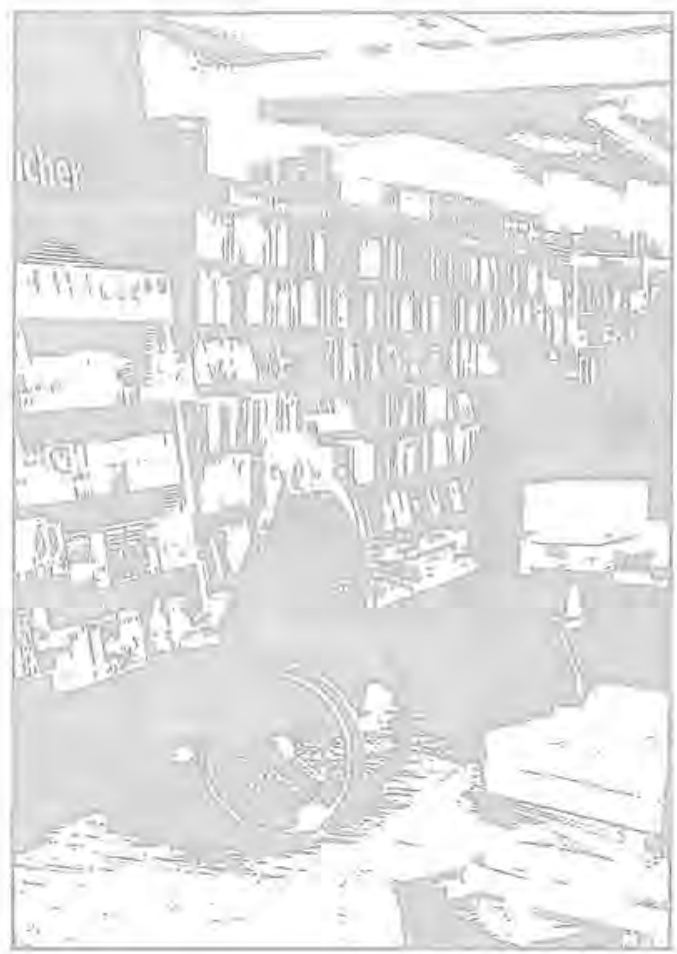

finančnim in kariernim portfeljem. Če nas finančna stroka in modrost učita, da je manj tvegano, če je naš finančni kapital razpršen med različne delnice, opcije, sklade ..., nas moderna teorija kariernega razvoja prepričuje, naj mislimo lateralno pri izgradnji kariernega kapitala.

Marjetina karierna pot predstavlja zanimiv primer. Skozi svojo karierno pot je pridobila veliko znanj in spretnosti na področju osebnih storitev, ravnanja s strankami in navezovanja učinkovitih odnosov z drugimi. Četudi bi poklic tajnice čez noč izginil, bi s svojimi sposobnostmi spretno lahko odigrala prenekatero drugo organizacijsko vlogo.

Analogijo med finančnim in kariernim kapitalom lahko peljemo celo tako daleč, da postavimo hipotezo preračunljivosti ljudi pri vlaganju v karierni kapital. Ljudje so lahko zelo racionalni, preračunljivi in ciljno usmerjeni pri vlaganju v svoj karierni kapital s točnim izračunom donosnosti investicije (ROI - return of investment). Toda če opazu- jemo obe karierni poti, pot Mateja in Marjete, lahko zagotovo trdimo, da ne enega ne drugega po vijugasti karierni poti ni vodil zgolj preračunljiv ekonomski interes, temveč prej temeljna želja po samorazvoju in interesu naučiti se nekaj novega.

\section{SKLEPNE MISLI}

Vpliv posameznika in njegovega kariernega kapitala na razvoj in poslovne usmeritve delovnih organizacij še nikoli ni bil tako očiten. Fluktuacija kadrov je čedalje večja. Če je dejstvo, da je posameznik večkrat menjal službo, še pred desetimi leti prestrašilo marsikaterega delodajalca, pa je to danes prej znak bogatega kariernega kapitala, ki lahko doprinese $\mathrm{k}$ razvoju So organizacije pripravljene akumulirati in sposobne izkoristiti karierni kapital zaposlenih? organizacije.

Kariernega kapitala ljudi ne predstavljata le znanje in sposobnosti, gradijo ga tudi osebne vrednote in osebne socialne mreže. Učeče se organizacije se znajo učiti od svojih zapošlenih.

Dejstvo, da karierno pot vodi pretežno želja po samorazvoju, v ospredje bolj kot kdaj koli prej postavlja pomen vseživljenjskega učenja. Potemtakem je želja po določenih znanjih torej tista, ki v globalnem okolju poslovanja usmerja našo karierno pot, ne pa organizacije s svojimi ponudbami. Slednje dejstvo pa nikogar, ki je sprejel koncept učeče se družbe, pravzaprav ne bi smelo presenetiti. Prišel je čas, ko morajo podjetja resnično postati učeče se organizacije.

\section{LITERATURA}

Arthur, M. B. (1994). The boundaryless career. Journal of Organisational Behaviour, št. 15, str. 295-306.

Baum, H. S. (1990). Organizational Membership. Albany, NNY: State University of New York, Press.

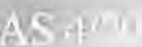


Brečko, D. (1998). Kako se odrasli spreminjamo. Didakta.

Brečko, D, (2001). Karierna sidra in načrtovanje izobraževanja. Raziskava.

Kanter, R. M. (2002). Careers and the wealth of nations: a macro prespective on the structure an implications of careers forms. V Arthur, Hall and Lawrence.

Katz, R. (1993). Organizational Stress and Early Socialization Experiences, V T. A. Beehr, R. S.

Maguire, S. R. Employer and occupational tenure. Montly Labour Review, June, str. 45-56.

McGarrell, E. J., Jr. (1983), "An Orientation System that Builds Productivity". Personnel, 60, vol. 6, str. 32-41.

Ostroff, C., Kozlowski, S. W. J. (1992). Organizational Socialization as a Learning Process: The Role of Information Acquisition. Personnel Psychology, vol 45, str. 849-874.

Premack, P. L., Wanous, J. P. (1985). A Meta-Analysis of Realistic Job Preview experiments. Journal of Applied Psychology, vol, 70, str. 706-719.

Shein, E. H. Career Dynamics: Matching individual and organizational needs.

Weiss, H. M. (1977). Subordinate Imitation of Supervisor Behavior: The Role of Modeling In Organizatioanl Socialization. Organizational Behavior and Human Performance, vol 19, str. 89-105. 